\title{
Making and Presentation of "Mooghurt" as a Healthy Drink to Improve Health Quality
}

\author{
Syamsurizal $^{1}$, Linda Advinda ${ }^{1}$, Resti Fervria ${ }^{1}$, Indra Hartanto ${ }^{1}$ dan Elsa Badriyya ${ }^{2}$ \\ ${ }^{I}$ Department of Biology, Faculty of Mathematics and Natural Sciences, Universitas Negeri Padang, Indonesia \\ ${ }^{2}$ Fakultas Farmasi, Universitas Andalas, Padang, Sumatera Barat, Indonesia \\ *Correspondence: syam_unp@fmipa.unp.ac.id
}

Diterima 17 Maret 2020 Disetujui 22 Maret 2020 Dipublikasikan 31 Maret 2020

\begin{abstract}
Mooghurt adalah merek dagang susu sapi fermentasi yang mirip dengan yoghurtyang dibuat oleh unit KWU himpunan mahasiswa jurusan Biologi FMIPA UNP. Mooghurt merupakan produk bioteknologi susu fermentasi yang bermanfaat untuk meningkatkan kesehatan saluran pencernaan, mengurangi kolesterol dalam darah, dan memberi stimulasi sistem saraf. Susu sapi segar sebagai bahan baku utama mooghurt diperoleh dari kota Padang Panjang. Padang Panjang merupakan salah satu sentra produksi susu sapi dengan kualitas bagus di Sumatera Barat. Produk peternakan susu sapi di Padang Panjang membuka peluang usaha bagi masyarakat sekitar, termasuk sivitas akademika jurusan Biologi FMIPA UNP dalam meningkatkan semangat wirausaha mahasiswa. Proses pembuatan Mooghurt terdiridari: 1) pembuatan starter; 2) pembuatan mooghurt; 3) pembuatan ekstrak buah atau jeli untuk pelengkap penyajiannya.
\end{abstract}

Key words: yoghurt, Lactobacillus bulgaricus dan Streptococus thermophilus

\section{PENDAHULUAN}

Kecenderungan meningkatnya daya tarik masyarakat terhadap produk minuman semakin tinggi. Hal ini dapat dilihat dari banyaknya produk-produk minuman yang muncul di pasaran seperti Thai tea, mango boom, teh keju dan juga produk minuman hasil fermentasi susu dengan berbagai macam varian rasa. Yoghurt merupakan minuman fermentasi yang memiliki rasa asam, manis dan menyegarkan (Kartikasari, 2014). Konsumen kurang menyukai yoghurt yang terlalu asam dan visikositas yang terlalu kental (Harjiyanti, 2013), oleh karena itu "Mooghurt" dibuat tidak terlalu asam, kekentalan sedang dan menggunakan perasa alami (Efendi, 2009). Upaya untuk meningkatkan kualitas yoghurt adalah dengan menambahkan perasa alami ekstrak buah seperti apel, kurma, nanas, mangga dan lainnya (Harjiyanti, 2013).

Susu sapi segar sebagai bahan baku utama mooghurt diperoleh dari kota Padang Panjang. Padang Panjang merupakan salah satu sentra produksi susu sapi dengan kualitas bagus di 
Sumatera Barat. Kesejahteraan peternak susu sapi di Padang Panjang, tergolong rendah dengan penghasilan Rp 1.900.000 setiap bulan dengan harga jual Rp 10.000/L (Dinas Pertanian dan Peternakan Padang Panjang, 2018). Keadaan ini perlu dicarikan solusinya dengan cara meningkatkan produksi dan harga jual susu sapi segar (Syamsurizal, 2018).

Produk peternakan susu sapi di Padang Panjang membuka peluang usaha bagi masyarakat sekitar seperti produk susu pasteurisasi, termasuk sivitas akademika jurusan Biologi FMIPA UNP dalam meningkatkan semangat wirausaha mahasiswa. Himpunan mahasiswa jurusan Biologi sudah memiliki unit KWU (kewirausahaan). Unit KWU selama ini bergerak dalam bidang penjualan produk makanan dan alat tulis dengan keuntungan yang tergolong kecil, Rp 455.000/ bulan (Olan Tryadi Sinaga, pengelola KWU).

Mooghurt dapat dibuat dengan berbagai varian rasa yaitu original, mangga, cokelat, sirsak, ubi ungu, jagung, strawberry, dan anggur (Nofrianti, 2013), (Abdulwadud, 2010)(Yani, 2006). Produk dikemas dalam botol jenis pet bowling berukuran $150 \mathrm{ml}$. Mooghurt dibuat dan dipasarkan di unit KWU Himpunan Mahasiswa Jurusan Biologi yang berlokasi di lantai dasar laboratorium Biologi. Tempat ini strategis sebagai tempat pemasaran produk .

Mooghurt merupakan produk fermentasi susu yang baik untuk kesehatan saluran pencernaan, mengurangi kolesterol dalam darah, dan memberi stimulasi sistem saraf (Triyono, 2010). Fermentasi erat kaitannya dengan bidang kajian bioteknologi (Puspita, 2014). Bioteknologi merupakan cabang ilmu yang dipelajari di Jurusan Biologi FMIPA UNP.

Mooghurt tidak hanya bermanfaat untuk meningkatkan kualitas hidup dan kesehatan masyarakat, tetapi juga dapat mengangkat potensi produksi susu sapi murni yang berada di daerah Padang Panjang Sumatera Barat. Mooghurt dirancang terutama untuk membangkit dan mengembangkan jiwa kewira usahaan mahasiswa di lingkungan jurusan Biologi FMIPA UNP.

Tujuan dari program PPUPIK adalah sebagai berikut.

a. Menciptakan wirausaha Mooghurt baru mandiri yang berbasis iptek.

b. Meningkatkan keterampilan manajemen usaha Mooghurt bagi masyarakat industri.

c. Menciptakan metode pelatihan kewirausahaan yang cocok bagi unit KWU mahasiswa jurusan Biologi FMIPA unp

Penanggulangan masalah kesejahteraan peternak yang rendah dan geliat usaha unit KWU HMJ Biologi yang belum optimal maka dikembangkan usaha produksi olahan susu sapi dengan nama Unit Bisnis "Mooghurt" Sivitas Akademika Jurusan Biologi FMIPA UNP. Mooghurt adalah merek dagang susu sapi fermentasi yang serupa dengan yoghurt.

\section{SOLUSI PERMASALAHAN}

Solusi penanggulangan masalah kesejahteraan peternak yang rendah dan geliat usaha unit KWU HMJ Biologi yang belum optimal maka dikembangkan usaha produksi olahan susu sapi dengan nama Unit Bisnis "Mooghurt" Sivitas Akademika Jurusan Biologi FMIPA UNP dengan rincian sebagai berikut:

1. Peternak diberi penyuluhan beternak sapi perah yang lebih ekonomis, lebih higienis sehingga kualitas dan kuantitas susu sapi segar meningkat.

2. Unit KWU himpunan mahasiswa jurusan Biologi diberi pelatihan persiapan, pembuatan dan pengemasan mooghurt.

3. Unit KWU himpunan mahasiswa jurusan Biologi diberi pelatihan pemasaran dan pembukuan usaha moghurt.

Dengan demikian diharapkan permasalahan masyarakat dan unit KWU dapat teratasi. 


\section{METODE PELAKSANAAN}

A. Bahan Baku

Bahan baku pembuatan Mooghurt bersumber dari ternak, berupa susu sapi murni. Pasokan susu sapi murni didapatkan langsung dari peternakan sapi yang berada di Padang Panjang. Produk susu sapi murni yang dipakai sebagai bahan dasar utama mendapat pengawasan langsung dari Dinas Pertanian dan peternakan Kota Padang Panjang. Varian rasa Mooghurt menggunakan sari buah alami. Buah yang digunakan didapatkan langsung dari pasar buah yang terdapat di Kota Padang. Alternatif sumber perolehan bahan baku dapat diperoleh dari peternakan sapi lainnya yang berada di wilayah Sumatera Barat.

B. Produksi

Produksi Mooghurt dilakukan langsung oleh tim Unit Bisnis "Mooghurt" Sivitas Akademika Jurusan Biologi.

1. Peralatan yang tersedia berupa kain saring, saringan, sendok, spatula, beaker glass $1000 \mathrm{ml}$, beaker glass $500 \mathrm{ml}$, beaker glass $100 \mathrm{ml}$, timbangan analitik, stopwatch, erlenmayer $250 \mathrm{ml}$, kertas wrapping, aluminium foil, spiritus, tisu, dan inkubator.

2. Namun terdapat beberapa kendala yaitu kekurangan peralatan yang dibutuhkan seperti jumlah blender, pisau, mesin cetak, lemari pendingin dan kompor listrik yang belum memadai.

\section{Proses Produksi}

Proses produksi Mooghurt tertera pada bagan di bawah ini.

1.Pembuatan komponen tambahan moghurt berupa jelly nenas, strawberry dan blueberry yang dipotong bentuk dadu.

2. Pembuatan moghurt

3. Memberi rasa moghurt: plan (original, nenas, strawberry dan blueberry)

4.Packing

\section{Pembuatan Perasa Alami Mooghurt}

Pada dasarnya semua buah dapat diolah menjadi perasa Mooghurt. Hanya perlu diingat bahwa tidak semua buah memiliki rasa yang enak setelah diolah menjadi perasa Mooghurt. Untuk menghasilkan perasa Mooghurt yang bermutu baik, buah yang akan diolah menjadi perasa Mooghurt harus benarbenar matang penuh. Buah seperti ini aromanya sangat kuat, sehingga hasil olahannya mempunyai aroma yang kuat dan wangi pula. Meskipun demikian pembuatan perasa Mooghurt dengan menggunakan buah mengkal juga masih disarankan.

Pencampuran buah matang dengan buah mengkal dapat memperbaiki konsistensi perasa Mooghurt yang dihasilkan. Hal ini disebabkan buah yang mengkal banyak mengandung pektin. Pektin ini sangat diperlukan dalam pembuatan perasa Mooghurt. Fungsinya ialah untuk menggumpalkan (mengentalkan). Dengan demikian cepatnya perasa Mooghurt mengental maka jumlah rendemen meningkat.

Untuk mengetahui kandungan pektin pada buah-buahan dapat dilakukan dengan cara sederhana yaitu dengan tes alkohol. Buah-buahan yang akan diuji diperas air buahnya, selanjutnya ditambahkan 3-4 sendok alkohol kedalam 1 sendok sari buah. Jika pada campuran banyak terdapat gumpalan kental berarti kandungan pektin pada buah tersebut tinggi. Sedangkan jika gumpalan yang terbentuk sedikit atau agak cair berarti kandungan pektinnya sedikit.

Perasa Mooghurt adalah makanan semi padat atau kental yang terbuat dari 45 bagian bubur buah dan 35 bagian gula. 
Campuran dipekatkan dengan pemasakan pada api sedang sampai kandungan gulanya menjadi $68 \%$. Berbagai macam perasa Mooghurt telah dipasarkan, diantaranya ialah perasa Mooghurt nenas, strawberry, srikaya, jeruk, dan sebagainya. Penggunaan perasa Mooghurt ialah untuk pelengkap hidangan roti, campuran pada pembuatan kue-kue, campuran es krim, dan sebagainya.

\section{a. Cara membuat perasa Mooghurt stroberi:}

Bahan

1. 1300 gram buah stroberi yang sudah dibuat daunnya

2. 900 gram gula pasir

3. $60 \mathrm{ml}$ air lemon

Langkah kerja:

1. Campur strawberry cincang dengan air dan gula pasir. Lalu panaskan di atas api sedang sambil diaduk sesekali saja sampai gula cair.

2. Setelah gula cair, kecilkan api, lalu masak terus sampai air menyusut dan strawberry menjadi halus, dan mulai mengental

3. Jika ingin lebih kental, masak lagi sampai air lebih menyusut

4. Angkat dari api (pada tahap ini, kalau strawberry masih dirasa terlalu kasar, boleh diblender sampai menjadi lembut).

5. Masukkan kedalam toples perasa Mooghurt yang telah disterilkan, lalu tutup rapat-rapat.

6. Masukkan toples ke dalam panci kukusan, lalu kukus selama 30 menit.

7. Angkat, dinginkan. Simpan di kulkas agar lebih tahan lama.

\section{b. Cara membuat perasa Mooghurt Nenas:}

Bahan

a. 500 gram nanas parut b. 100 gram gula pasir (sesuaikan selera saja kalau soal manis dan tidaknya perasa Mooghurt, karena tergantung nanas yang kita gunakan juga sudah manis atau belum )

c. 1/8 sendok teh garam

d. $3 \mathrm{~cm}$ kayu manis batangan

Langkah kerja

a. Pilihlan nanas yang matang benar, berwarna kuning tua dan nampak ranum segar, agar aroma perasa Mooghurtnya semakin harum wangi nanas matang.

b. Parut nanas dengan parutan yang tajam, sehingga lebih mudah daripad memakai parutan kelapa.

c. Jangan menggunakan blender untuk nanas yang akan di buat perasa Mooghurt karena akan butuh air, jadi nanti akan semakin lama proses memasaknya.

d. Panaskan nanas terlebih dahulu tanpa di campur gula dengan api sedang sampai air nanas menguap/ menyusut.

e. Masukkan gula dan kayu manis, hal ini akan mempercepat proses pembuatan perasa Mooghurt nanas.

f. Masak hingga perasa Mooghurt kesat dan kering dan tambahkan sedikit garam, agar rasa perasa Mooghurt nanas makin enak.

g. Jika ingin perasa Mooghurt nanas yang semakin kesat dan kering, ratakan di loyang tipis-tipis, kemudian panggang sebentar di oven.

\section{Pembuatan Mooghurt}

Bahan Yoghurt :

a. Siapkan 1 liter susu murni. Boleh menggunakan susu kemasan tetapi lebih baik susu murni.

b. Bibit yoghurt sebanyak 5\% dari banyaknya susu murni. Untuk 1 liter susu 
murni bisa menggunakan sekitar $50 \mathrm{~mL}$ atau $2 \mathrm{sdm}$ bibit yoghurt. Bisa dibeli di supermarket.

Cara Membuat Mooghurt :

1. Panaskan susu murni di atas api kecil sambil terus diaduk selama 30 menit dan jaga agar susu tidak sampai mendidih supaya protein susu tidak rusak.

2. Setelah 30 menit, angkat susu dan dinginkan hingga hangat kuku dalam suhu ruangan

3. Masukan bibit yoghurt lalu aduk sampai rata dengan menggunakan alat pengaduk steril. Bila kesulitan mencari alat pengaduk dapat menggunakan spatula kayu yang sebelumnya sudah disiram menggunakan air panas sebagai proses sterilisasi alat.

4. Apabila sudah selesai masukan ke wadah tertutup lalu tutup dengan serbet untuk menciptakan kondisi gelap yang adalah syarat hidup bakteri fermentasi selama 20 24 jam.

5. Sesudah 20-24 jam akan muncul lapisan berwarna kekuningan kental di atas permukaannya. Apabila masih kurang kental atau kurang asam bisa dilebihkan lagi waktunya. Bila dirasa sudah pas, aduk menggunakan alat steril sampai tercampur rata.

6. Jika hendak membuat yoghurt lagi, pisahkan beberapa sendok ke dalam cup kecil. Inilah yang kelak akan menjadi starter apabila hendak membuat yoghurt lagi jadi tidak perlu ke supermarket membeli bibit baru. Cup berisi yoghurt tersebut ditutup rapat, tuliskan tanggal pembuatannya lalu masukan kulkas. Disarankan maksimal seminggu supaya tetap terjaga rasa dan sterilitasnya.

7. Bila sudah siap, bisa ditambahkan sirup atau buah-buahan sesuai selera.

\section{Tips Cara Membuat Mooghurt :}

1. Pastikan proses fermentasi yoghurt menggunakan wadah kedap udara. Wadah yang tertutup rapat akan melancarkan proses fermentasi

2. Saat membeli yoghurt plain, lihat dulu masa kadaluarsanya. Kalau sudah expired maka proses pembuatan yoghurt tidak akan berhasil

3. Saat memasukan susu ke wadah, pastikan susu dalam keadaan hangat. Tidak panas dan tidak terlalu dingin

4. Bibit yoghurt yang dimaksud adalah produk yoghurt seperti cimory, biokul, dst. Disebut bibit karena itulah yang akan menjadi biang penghasil yoghurt. Saat memilih bibit pilihlah bibit yang terdapat tulisan "Live Culture" pada kemasannya supaya bakteri fermentasi dapat berkembang. Live culture yang dimaksud pada umumnya adalah bakteri Lactobacillus Bulgaricus dan Streptococcus Thermophilus

5. Pastikan perbandingan susu murni dan bibitnya tepat. Apabila nanti yoghurtnya terlampau kental, itu artinya terlalu banyak bibit. Bila terlalu encer berarti terlalu sedikit.

Peralatan yang sudah tersedia di ruang produksi Mooghurt diantaranya adalah kain saring, saringan, sendok, spatula, beaker glass $1000 \mathrm{ml}$, beaker glass $500 \mathrm{ml}$, beaker glass 100 $\mathrm{ml}$, timbangan analitik, stopwatch, erlenmeyer $250 \mathrm{ml}$, kertas wrapping, aluminium foil, spiritus, tisu, dan inkubator. Terdapat beberapa peralatan yang akan dibeli untuk kelancaran produksi Mooghurt, diantaranya mesin cetak, blender, pisau, lemari pendingin, dan kompor listrik.

Sistem penjaminan mutu yang diterapkan melalui pengontrolan produksi Mooghurt oleh tenaga ahli bidang bioteknologi. Kegiatan pengontrolan yang dilakukan diantaranya adalah pengontrolan kebersihan ruang, sterilisasi alat, 
kualitas susu murni dan buah yang digunakan. Perasa Mooghurt, kebersihan alat dan bahan, kebersihan karyawan dalam memproduksi Mooghurt juga dikontrol.

Produk Mooghurt dipasarkan di unit KWU himpunan mahasiswa jurusan Biologi FMIPA, Universitas Negeri Padang. Pemasaran produk dilakukan dua kali dalam seminggu, produk Mooghurt dipasarkan dalam keadaan dingin, maka Mooghurt disimpan di dalam lemari pendingin yang tersedia di KOPMA. Harga jual untuk satu botol Mooghurt berukuran $240 \mathrm{ml}$ adalah Rp 5000,00. Sasaran dari produk ini adalah semua kalangan, baik mahasiswa maupun dosen dan karyawan yang berada di lingkungan FMIPA UNP.

Selama produksi tiga tahun ke depan, tim PPUPIK Mooghurt memperkerjakan 3 orang mahasiswa. Gaji dari setiap karyawan dibayarkan sekali sebulan sebesar Rp 1200000. Melalui keterlibatan para karyawan dalam produksi Mooghurt di Jurusan Biologi, FMIPA UNP, perasa Mooghurt mendapatkan keuntungan finansial, mereka juga mendapatkan keuntungan wawasan ilmu dan pengalaman. Wawasan dan pengalaman yang diperoleh dapat dikembangkan dalam kehidupan sehari-hari, seperti membuka lapangan usaha sendiri.

\section{Pemasaran}

Luasan pasar produk PPUPIK ini meliputi pasar lokal, nasional maupun eksport. Teknik pemasaran produk PPUPIK ini akan menggunakan berbagai teknik, mulai dari konvensional untuk konsumen lokal, maupun ecommerce untuk konsumen pengguna internet. Moghurt ini adalah minuman sehari-hari yang kaya nutrisi yang sangat bermanfaat untuk kesehatan, maka target konsumen produk PPUPIK ini akan menjangkau semua level sosial masyarakat, baik lokal, regional. Lokasi pemasaran Mooghurt dapat dilihat pada gambar 1.

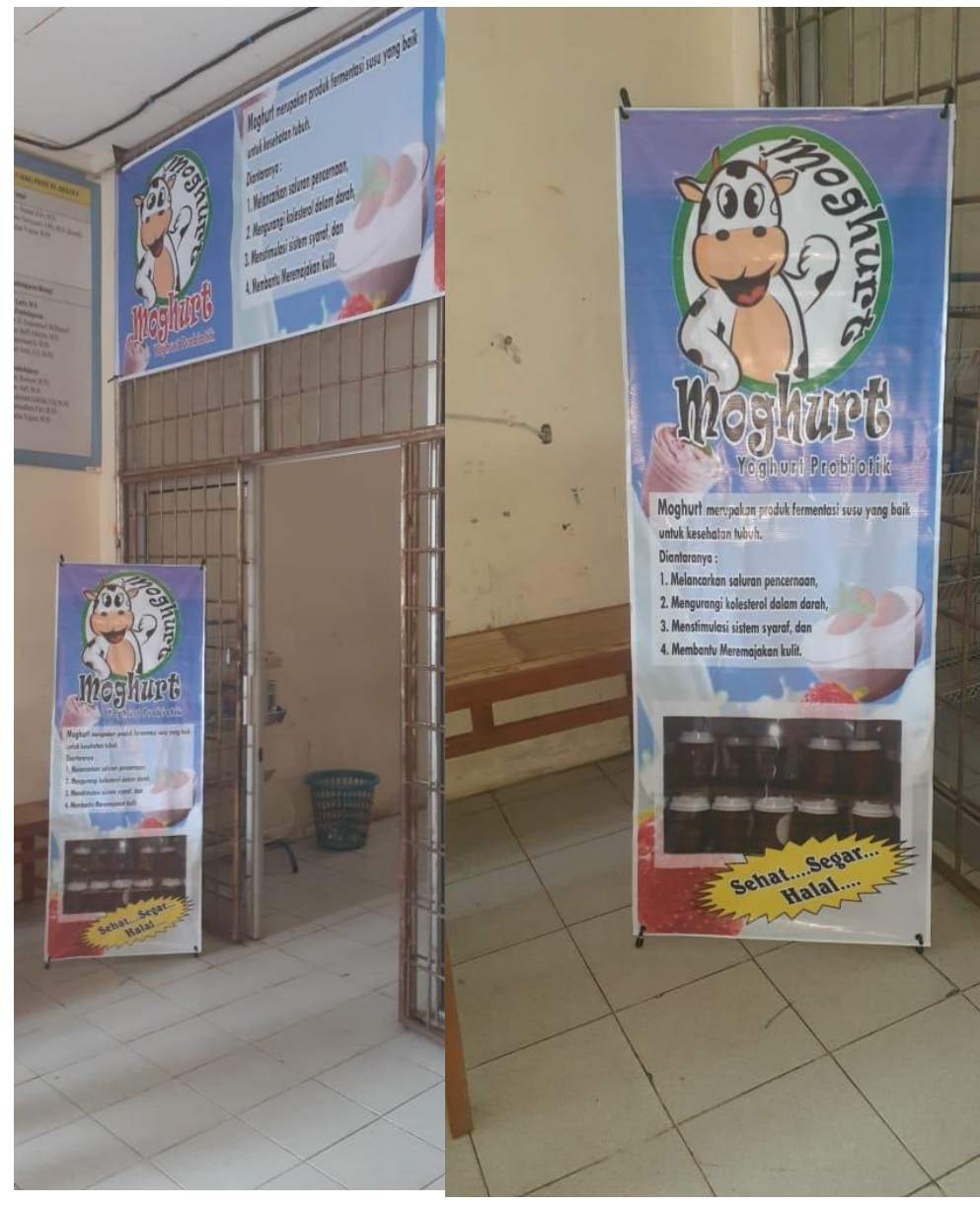

Gambar 1. Lokasi pemasaran mooghurt di laboratorium Biologi FMIPA UNP

\section{KESIMPULAN}

Berdasarkan capaian yang telah diuraikan di atas dapat disimpulkan: 1) Sudah berhasil membuat mooghurt dengan perasa alami dari ekstrak nanas, strawberi; 2) Produk PPUPIK sudah dipasarkan di lingkungan FMIPA UNP; 3) Program PPUPIK berhasil melatih dan membentuk kelompok wirausaha baru dikalangan mahasiswa jurusan Biologi FMIPA UNP; 4) Produk PPUPIK belum memberikan keuntungan finansial yang signifikan kepada Universitas Negeri $\mathrm{Pa}$ dang maupun kepada pengelola program Unit Bisnis "Mooghurt" Sivitas Akademika Jurusan Biologi FMIPA UNP karena pengelola program sebagian besar mahasiswa yang aktif kuliah. 


\section{Ucapan Terima Kasih}

Ucapan terima kasih disampaikan kepada Rektor UNP sebagai sponsor kegiatan Program Pengembangan Usaha Produk Intelektual Kampus (PPUPIK) melalui dana DIPAUNPNomor: 182/UN.35/LT/2019 Tanggal: 22 April 2019

\section{DAFTAR PUSTAKA}

Abdulwadud, Syura A Ahmad. (2010). Strategi Pengembangan Usaha Dengan Pendekatan Blue Ocean Strategy. (Sarjana), IPB, IPB.

Efendi, Mustofa Helmi; Sorini hatini; Lusiastuti. (2009). Peningkatan Kualitas Yoghurt Dari Susu Kambing Dengan Penambahan Bubuk Susu Skim Dan Pengaturan Suhu Pemeraman. Med.Eksakta, 8(3), 185-192.

Fatati, Adriani; Sri Novianti;. (2014). Usaha IbIKK Kambing Merah. Jurnal Pengabdian Pada Masyarakat, 4(1), 1-10.

Harjiyanti, Pramono, Mulyani. (2013). Total Asam, Viskositas dan Kesukaan pada Yoghurt Drink dengan Perisa dari Buah Mangga sebagai Perisa. Aplikasi Tekhnologi Pangan, 2(2), 104-107.
Kartikasari, Dian; Fithri Choirun Nisa. (2014). Pengaruh Penambahan Sari Buah Sirsak Dan Lama Fermentasi Terhadap Karakteristik Fisik Dan Kimia Yoghurt. Jurnal Pangan dan Agroindustri, 2(4), 239-248.

Nofrianti, R; F. Azima; R. Eliyasmi. (2013). Pengaruh Penambahan Madu Terhadap Mutu Yogurt Jagung. Jurnal Aplikasi Teknologi Pangan, 2(2), 60-68.

Puspita, Suci dewi; Taslim; Anita Fitriani. (2014). Pengaruh Harga, Kualitas Produk, Dan Citra Merek Terhadap Keputusan Pembelian Yoghurt. Universitas Padjajaran, Unpadj.

Syamsurizal, Linda advinda, Resti Fevria dan Maizirwan.(2018). Business Unit" Mooghurt" Academic Community Biology Department FMIPA Universitas Negeri Padang, Pelita Eksakta, 1(2), 82-90.

Triyono, Agus. (2010). Mempelajari Pengaruh Maltodekstrin Dan Susu Skim Terhadap Karakteristik Yoghurt Kacang Hijau (Phaseolus radiatus L.). Rekayasa Kimia dan Proses, 1(1), 1-9.

Yani, A; B.P. Purwanto. (2006). Pengaruh Iklim Mikro terhadap Respons Fisiologis Sapi Peranakan Fries Holland dan Modifikasi Lingkungan untuk Meningkatkan Produktivitasnya. Media Pertanian, 29(1), 35-46. 